\title{
Anesthesia-related status epilepticus after fiber optic colonoscopy in a child
}

\author{
Shiyu Shu*
}

Ministry of Education Key Laboratory of Child Development and Disorders, Key Laboratory of Pediatrics in Chongqing, Chongqing International Science and Technology Cooperation Center for Child Development and Disorders, Department of Anesthesiology, Children's Hospital, Chongqing Medical University, Chongqing, China.

*Corresponding author's e-mail address: shushiyu@hotmail.com

Published online: 6 July 2015 (version 1)

Cite as: Shu S., ScienceOpen Research 2015 (DOI: 10.14293/S2199-1006.1.SOR-MED.AXK5RB.v1)

Reviewing status: Please note that this article is under continuous review. For the current reviewing status and the latest referee's comments please click here or scan the QR code at the end of this article.

Primary discipline: Medicine

Secondary discipline: Anesthesiology \& Pain management

Keywords: Pediatric anesthesia, Seizure-like phenomenon, Propofol, Remifentanil

\begin{abstract}
A healthy, 8-year-old girl with a history of hematochezia underwent an uneventful fiber optic colonoscopy with propofol anesthesia. During the postoperative recovery period, she experienced acute-onset muscle rigidity, loss of consciousness, apnea, hypoxia, and hyperthermia. She was administered cardiopulmonary resuscitation and was treated with naloxone, mannitol, and midazolam. She regained consciousness after 14 hours. She underwent cerebral function rehabilitation and was discharged in 1 month without obvious neurologic sequelae. This case illustrates that propofol may affect the developing brain differently from the adult brain. Propofol-induced seizures can lead to life-threatening status epilepticus in children. Immediate diagnosis and effective treatment are essential.
\end{abstract}

\section{INTRODUCTION}

In the perioperative period, seizures can occur unexpectedly with devastating and life-threatening consequences, particularly in children. Seizures may manifest clinically as loss of consciousness and clonic-tonic motor activity resulting from abnormal and rhythmic neuronal discharges in the brain. Numerous factors increase the risk of perioperative seizures, including preexisting epilepsy; adverse medication reactions; central nervous system injury or undiagnosed structural lesions; and low seizure threshold associated with some infectious diseases, metabolic disorders, hydrocephalus, or celiac disease. Prolonged seizures that are refractory to medications constitute status epilepticus, which is considered a medical emergency.

Propofol (2,6-diisopropylphenol), a $\gamma$-aminobutyric-mediated inhibitor of excitatory neurotransmitters, is commonly used for induction and maintenance of anesthesia because it takes effect and wears off quickly and has few adverse effects. It is also a popular alternative to benzodiazepines for treating status epilepticus [1]. However, the term propofol-related seizure-like phenomena (SLP) [2] is used to describe the generalized myoclonus associated with propofol because simultaneous electroencephalogram (EEG) recordings of cortical epileptic activity have not been documented. Here, we report a pediatric case of propofol-induced seizure-like activity. The patient, the patient's family, and the local Institutional Review Board reviewed the case report and gave permission for the authors to publish the report.

\section{CASE REPORT}

An 8-year-old, 35-kg girl underwent fiber optic colonoscopy for evaluation of hematochezia. She was otherwise healthy with normal intelligence.

Before anesthesia induction, her heart rate (HR) was 96/min, spontaneous breathing was 25 times/min, oxygen saturation by pulse oximetry $\left(\mathrm{SpO}_{2}\right)$ was $100 \%$, and blood pressure (BP) by noninvasive cuff was $102 / 60 \mathrm{mmHg}$. The patient was anesthetized with $0.5 \mathrm{mg}(0.01 \mathrm{mg} / \mathrm{kg})$ midazolam, $20 \mu \mathrm{g}(0.57 \mu \mathrm{g} / \mathrm{kg})$ remifentanil, and $70 \mathrm{mg}(2 \mathrm{mg} / \mathrm{kg})$ propofol. Oxygen was delivered by nasal cannula at $1 \mathrm{~L} / \mathrm{min}$. An intravenous infusion of $8 \mathrm{mg} \cdot \mathrm{kg}^{-1} \cdot \mathrm{h}^{-1}\left(133 \mu \mathrm{g} \mathrm{kg}{ }^{-1} \mathrm{~min}^{-1}\right.$ ) propofol was used to maintain anesthesia. The colonoscopy was uneventful and lasted 13 minutes. Endoscopic evaluation revealed no anatomic abnormalities. During the endoscopy, the patient's vital signs were stable. After the procedure, the propofol infusion was stopped. The patient was spontaneously breathing (20 times/min) and arousable to mildly painful stimulus. Her HR was $100 / \mathrm{min}, \mathrm{BP} 100 / 65$, and $\mathrm{SpO}_{2} 98 \%$. After approximately 10 minutes in the recovery room, the patient developed peri-oral cyanosis, trismus, guttural vocalizations, limb rigidity, chest wall stiffness, and trembling. At that time HR was $10 / \mathrm{min}$ and $\mathrm{SpO}_{2}$ was $40 \%$. Chest compressions were performed immediately, and bag-mask ventilation was initiated with oxygen at $\mathrm{FiO}_{2} 100 \%$. The HR rapidly increased to $102 / \mathrm{min}$. 
Because of laryngospasm and chest wall stiffness, bag-mask ventilation did not result in good chest movement. The peri-oral cyanosis resolved after 30 seconds of bag-mask ventilation, but the patient remained apneic. At that time, the vital signs were HR 105/min, $\mathrm{SpO}_{2}$ 90\%, and $\mathrm{BP} 90 / 50 \mathrm{mmHg}$.

Because the differential diagnosis for apnea included respiratory depression from residual anesthetic, $0.2 \mathrm{mg}$ of naloxone $(5.7 \mu \mathrm{g} / \mathrm{kg})$ was injected intravenously. Spontaneous ventilation resumed at a rate of 5 times/min. Her pupils were approximately $2 \mathrm{~mm}$ in diameter, equal, round, and reactive to light. Naloxone $0.2 \mathrm{mg}$ was delivered again, and spontaneous breathing gradually increased to $15-20$ times/min. The patient was not intubated.

Oxygen was delivered through a nasal catheter. At that time, the HR was $110 / \mathrm{min}, \mathrm{SpO}_{2}$ was $100 \%$, and the patient was breathing spontaneously at approximately 20 times/min. Her pupils were reactive to light, equal bilaterally, round, and approximately $3 \mathrm{~mm}$ in diameter. To alleviate potential cerebral edema, $100 \mathrm{~mL}$ of mannitol $(0.57 \mathrm{~g} / \mathrm{kg})$ was delivered rapidly. The patient coughed under sputum suction stimuli, but trismus, limb rigidity, and trembling were still observed.

Blood gas analysis revealed that the child did not have respiratory acidosis and was adequately oxygenated. Fifty milliliters of $5 \% \mathrm{NaHCO}_{3}$ was administered intravenously to treat metabolic acidosis. The patient's temperature was $38.5^{\circ} \mathrm{C}$, making malignant hyperthermia unlikely.

After a second intravenous administration of $50 \mathrm{~mL}$ mannitol, the patient was shivering and grinding her teeth with increased muscle tension. Pupil diameter was $5 \mathrm{~mm}$ with good light reflex. Although $4 \mathrm{mg}$ midazolam was given to slightly ease muscle tension, paroxysmal limb muscle rigidity, opisthotonus, and disturbance of consciousness were still observed. Because of elevated body temperature, an ice pillow was used to cool the head, and the main artery was wiped with alcohol. The patient was taken to the pediatric intensive care unit (PICU). Blood gas analysis results obtained approximately 16 minutes after the first analysis showed near-normal values.

Arriving at the PICU, the patient's temperature was $36.8^{\circ} \mathrm{C}$. Her breathing rate was $22 / \mathrm{min}, \mathrm{HR}$ was $83 / \mathrm{min}$, BP was 115 / $57 \mathrm{mmHg}$, and $\mathrm{SpO}_{2}$ was $100 \%$. Pupils were both $4 \mathrm{~mm}$, large and round, with a sensitive light reflex. Bilateral tonsils showed grade II enlargement, and the pharynx was congestion-free. The expiratory phase was extended. Neurologic exam revealed the following results: knee-jerk, left (3/5), right (3/5); abdominal reflex was not elicited; Babinski sign, left $(+)$, right (+); Kernig sign, left $(-)$, right $(-)$; and Brudzinski sign, left $(-)$, right $(-)$. Muscle tension in the four limbs was elevated, and paroxysmal muscle tension increased after stimulation. The patient was stabilized with drug sedation, and the sleep spindle disappeared after stimuli. High-amplitude slow-wave background and $\delta \theta$ mixed activities were seen in the forehead area; no specific changes in EEG trajectories were observed when the patient was trembling (Figure 1).
In the PICU, the patient received cold cap therapy; oxygen by nasal cannula at $2 \mathrm{~L} / \mathrm{min}$; continuous infusion of midazolam (5 $\mu \mathrm{g} \mathrm{kg}^{-1} \mathrm{~min}^{-1}$ ); sulindac (amoxicillin and sulbactam); repeated doses of mannitol to reduce intracranial pressure to prevent bradycardia, hypertension, unresponsive/unequal pupils; nalmefene hydrochloride for awakening [3]; and deproteinized calf blood serum injection to nourish the brain cells. Stimulation of the patient was minimized to prevent further increases in muscle tension. Myocardial enzymes, coagulation, and liver and kidney function remained within normal limits.

Two hours after being admitted to the PICU, the patient was still unconsciousness with elevated muscle tension. Paroxysmal limb muscle rigidity occurred with slight stimulation. At 8 hours, the patient was confused, had involuntary limb activity, and exhibited paroxysmal limb muscle rigidity after slight stimulation. At 13 hours, the muscle tension and involuntary limb movements had decreased, and the patient could make sounds. At 14 hours, consciousness was restored, but lethargy persisted. The patient could say "pain" when responding to pain stimulation but was not fluent in verbal exchanges. During the waking process, vital signs were stable. Babinski's sign was left $(+)$, right $(+)$; and blood analysis was normal. At 20 hours after PICU admission, the patient could eat with assistance.

The EEG still showed abnormalities after 3 days (Figure 2). Although background activity had recovered somewhat since the first EEG, it was still slow in the waking period, and $\theta$ activity was elevated. Brain CT (Figure 3) revealed no obvious abnormalities.

After 10 days of hyperbaric oxygen therapy, the EEG (Figure 4) indicated a clear background with $\theta$ activity slightly increased by $5-7 \mathrm{~Hz}$, a significant improvement over the initial EEG background.

The results of a Wechsler intelligence test suggested that the patient had a language intelligence quotient (IQ) of 137, a performance test IQ of 120, and a high total IQ of 135. These scores indicate that the patient functioned at an ageappropriate level without cognitive impairment. During the tests, the patient's attention span was approximately 10 minutes. Strong mathematic and memory skills and lower scores on mapping and arranging suggested lower levels of logical reasoning.

The EEG of the patient normalized after another 10 days, and the patient was discharged.

\section{DISCUSSION}

The doctors in the PICU believed that convulsions in this child were due to hypoxia. Hypoxia can occur as a result of airway occlusion, a mucus plug, and anesthesia-induced respiratory depression or apnea. The fact that the patient's mouth and cheeks turned red after pressurized oxygen was applied confirms this point. However, the anesthesiologists believed that only hypoxia lasting at least 4 minutes would cause the serious convulsive state observed in this patient, and hypoxia 
(a)

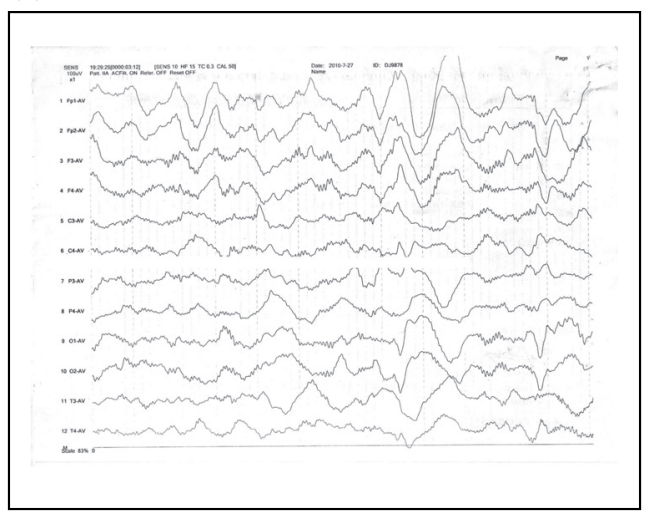

(c)

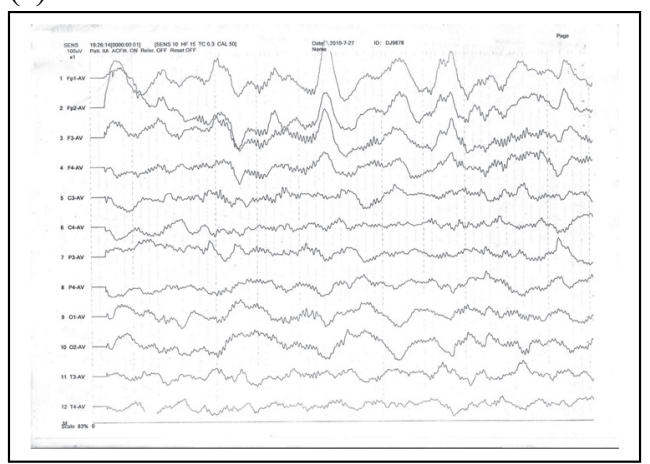

(e)

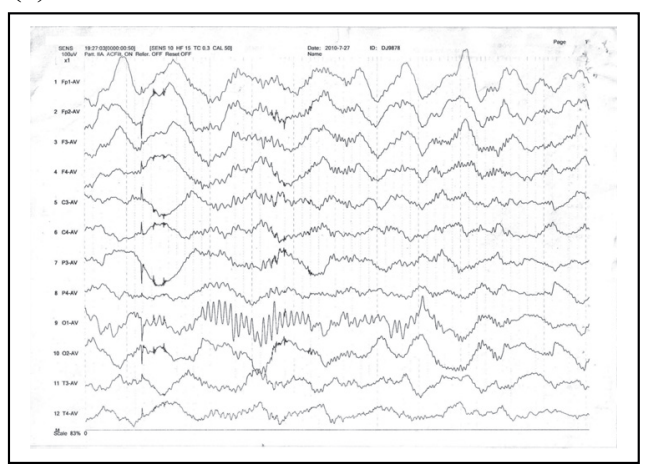

(b)

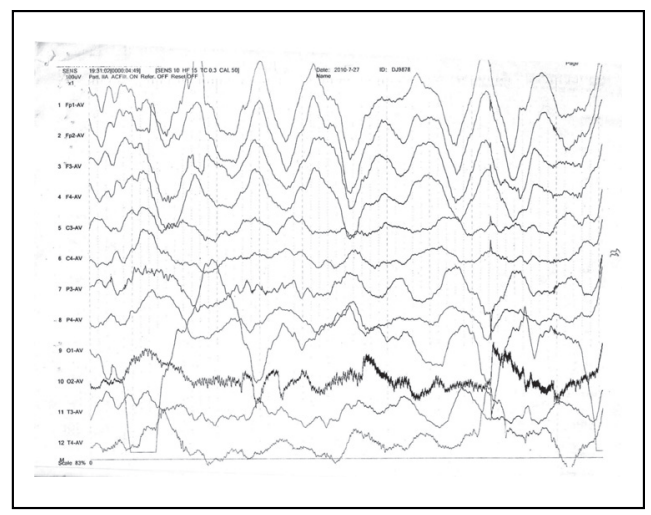

(d)

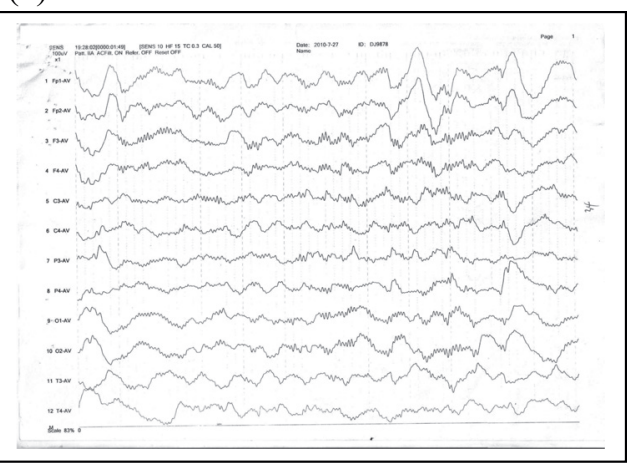


(a)

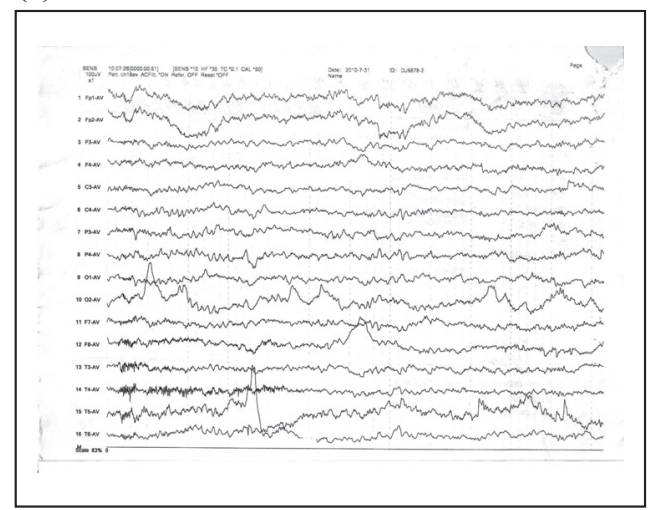

(b)

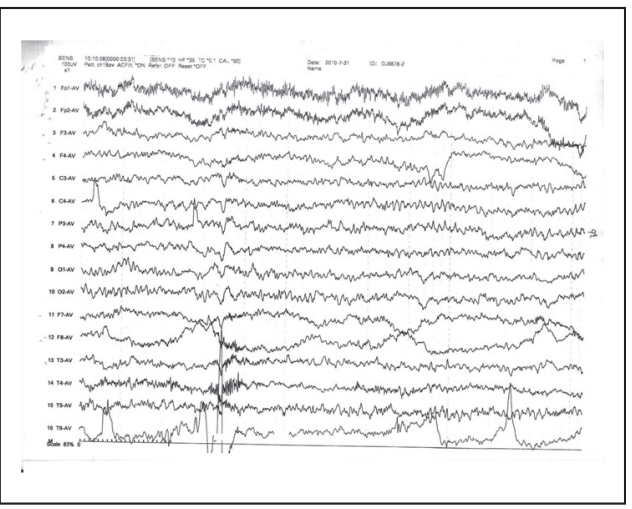

Figure 2. Representative EEG segments of the child 3 days after the procedure. A, Awake with closed eyes. B, Awake and moving.

SLP have been observed in patients with and without a history of epilepsy or seizures and do not always respond to benzodiazepines [10]. Consequently, propofol-induced SLP is highly complex.
The debate is ongoing regarding whether propofol exhibits pro- or anticonvulsant effects [11], and whether it should be used in patients with epilepsy $[12,13]$. Prudence suggests that patients who experience SLP should not be given propofol
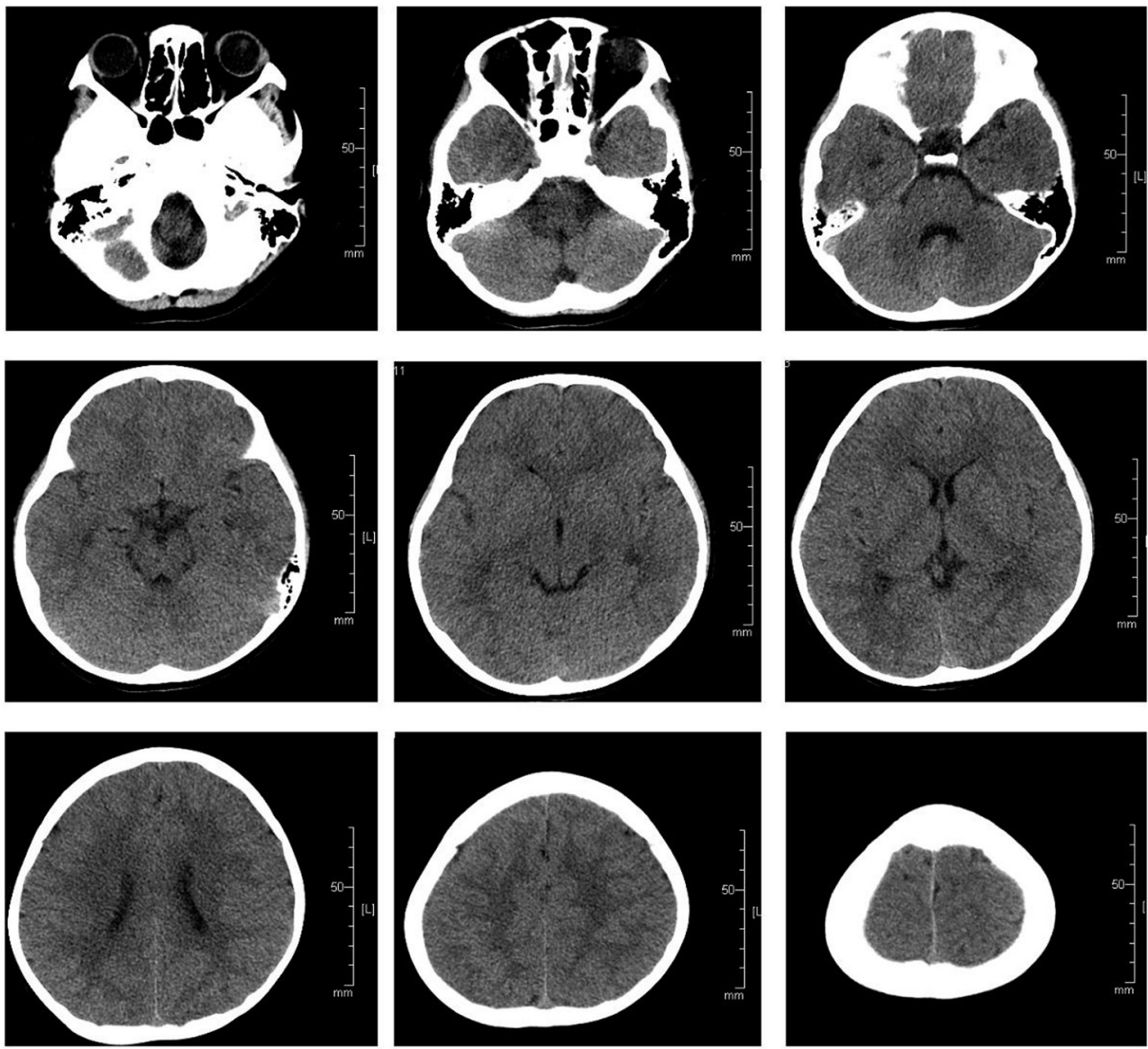

Figure 3. Brain $\mathrm{CT}$ of the child after recovery. 
(a)

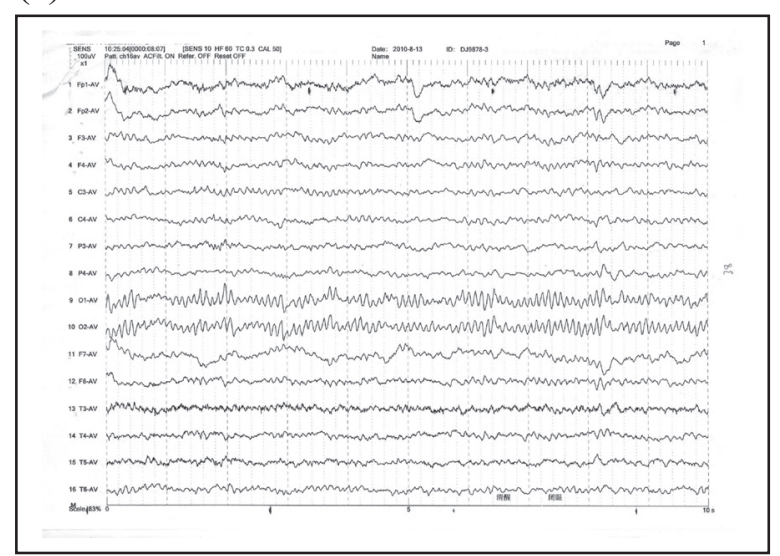

(b)

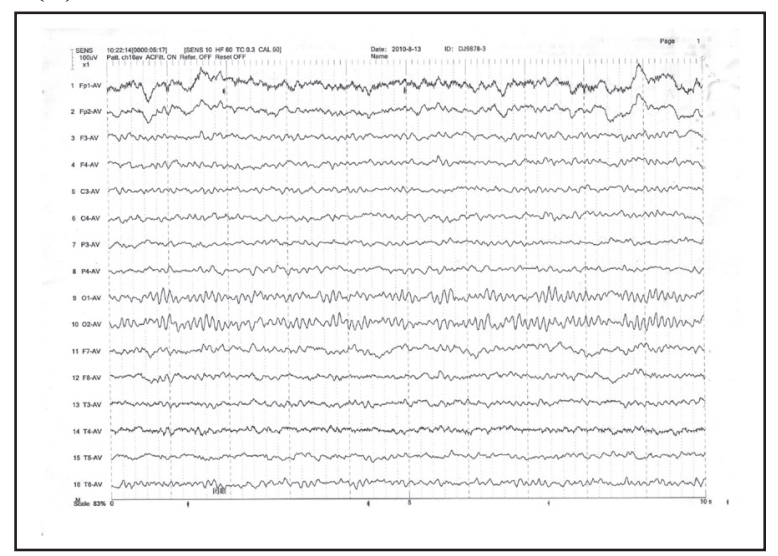

Figure 4. Representative EEG segments of the child 10 days after the procedure. A, Awake with closed eyes. B, Sleeping.

again. Zubair et al. [14] proposed that SLP associated with propofol withdrawal may not be ictal in nature and should not lead to unnecessary resumption of propofol infusion without documentation of an epileptic origin by EEG.

Remifentanil, an opioid with a unique pharmacokinetic profile, has been used with propofol in electroconvulsive therapy $[15,16]$. Blair et al. [17] described a 4-year-old child who developed epilepsy after being treated with remifentanil. The mechanism of action is unclear, but it may be related to the excitement of the epileptic focus. Combining propofol use with midazolam or reducing the amount of remifentanil can prevent the occurrence of epilepsy.

In conclusion, anesthesia-induced SLP cannot be avoided. Immediate diagnosis, rapid termination of seizures, improving imbalances of the physiologic environment, and protecting the brain are effective ways to help promote quick recovery.

\section{ACKNOWLEDGMENT}

We would like to thank Professor Raymond C. Koehler (Department of Anesthesiology/Critical Care Medicine, The Johns Hopkins University School of Medicine) for some good advices and Mrs. Chen Jianrong (X-ray Department of Children's Hospital of Chongqing Medical University, China) for supplying the CT scanning film. No external funding and no competing interests are declared.

\section{REFERENCES}

[1] Prabhakar H, Bindra A, Singh GP, Kalaivani M. Propofol versus thiopental sodium for the treatment of refractory status epilepticus (Review). Evid Based Child Health. 2013;8(4):1488-508. doi:10.1002/ebch.1929

[2] Walder B, Tramèr MR, Seeck M. Seizure-like phenomena and propofol: a systematic review. Neurology. 2002;58(9):1327-32. doi:10.1212/WNL.58.9.1327

[3] Kaplan JL, Marx JA, Calabro JJ, Gin-Shaw SL, Spiller JD, Spivey WL, Gaddis GM, Zhao N, Harchelroad, FP. Double-blind, randomized study of nalmefene and naloxone in emergency department patients with suspected narcotic overdose. Ann Emerg Med. 1999;34(1):42-50. doi:10.1016/S0196-0644(99) 70270-2

[4] Stanziano M, Foglia C, Soddu A, Gargano F, Papa M. Post-anoxic vegetative state: imaging and prognostic perspectives. Funct Neurol. 2011;26(1):45-50. Review.

[5] Gillam-Krakauer M, Carter BS. Neonatal hypoxia and seizures. Pediatric Rev. 2012;33(9):387-96. doi:10.1542/pir.33-9-387

[6] Hickey KS, Martin DF, Chuidian FX. Propofol-induced seizurelike phenomena. J Emerg Med. 2005;29(4):447-9. doi:10.1016/ j.jemermed.2005.05.009

[7] Meyer P, Langlois C, Soëte S, Leydet J, Echenne B, Rivier F, Bonafé A, Roubertie A. Unexpected neurological sequelae following propofol anesthesia in infants: three case reports. Brain Dev. 2010;32(10):872-8. doi:10.1016/j.braindev.2009.11.011

[8] Yanaru T, Sugi Y, Higa K, Shono S, Katori K, Nitahiara K. Propofol-induced generalized tonic-clonic seizure: a case report. Masui. 2010;59(8):1036-8.

[9] Zeiler SR, Kaplan PW. Propofol withdrawal seizures (or not). Seizure. 2008;17(7):665-7. doi:10.1016/j.seizure.2008.03.004

[10] Prasad A, Worrall BB, Betram EH, Bleck TP. Propofol and midazolam in the treatment of refractory status of epilepticus. Epilepsia. 2001;42(3):380-6. doi:10.1046/j.1528-1157.2001. 0420s8006.x

[11] Borgeat A. Propofol: pro- or anticonvulsant? Eur J Anaesthesiol. 1997;14:17-20. doi:10.1097/00003643-199705001-00004

[12] Meyer S, Shamdeen MG, Kegel B, Mencke T, Gottschling S, Gortner L, Grundmann U. Effect of propofol on seizure-like phenomena and electroencephalographic activity in children with epilepsy vs children with learning difficulties. Anaesthesia. 2006;61(11):1040-7. doi:10.1111/j.1365-2044.2006.04782.x

[13] Power KN, Flaatten H, Gilhus NE, Engelsen BA. Propofol treatment in adult refractory status epilepticus. Mortality risk and outcome. Epilepsy Res. 2011;94(1-2):53-60. doi:10.1016/ j.eplepsyres.2011.01.006

[14] Zubair S, Patton T, Smithson K, Sonmezturk HH, Arain A, AbouKhalil B. Propofol withdrawal seizures: non-epileptic nature of seizures in a patient with recently controlled status epilepticus. Epileptic Disord. 2011;13:107-10.

[15] Dinwiddie SH, Glick DB, Goldman MB. The effect of propofolremifentanil anesthesia on selected seizure quality indices in electroconvulsive therapy. Brain Stimul. 2012;5(3):402-7. doi:10.1016/j.brs.2011.06.008 
[16] Nishikawa K, Higuchi M, Kawagishi T, Shimodate Y, Yamakage M. Effect of divided supplementation of remifentanil on seizure duration and hemodynamic responses during electroconvulsive therapy under propofol anaesthesia. J Anesth. 2011;25(1): 29-33. doi:10.1007/s00540-010-1049-4

[17] Blair JM, Hill DA, Wilson CM, Fee JPH. Assessment of tracheal intubation in children after induction with propofol and different doses of remifentanil. Anaesthesia. 2004;59(1):27-33. doi:10.1111/j.1365-2044.2004.03524.x

\section{COMPETING INTERESTS}

The author declares no competing interests.

\section{PUBLISHING NOTES}

(C) 2015 Shiyu Shu. This work has been published open access under Creative Commons Attribution License CC BY 4.0, which permits unrestricted use, distribution, and reproduction in any medium, provided the original work is properly cited. Conditions, terms of use and publishing policy can be found at www.scienceopen.com.

Please note that this article may not have been peer reviewed yet and is under continuous post-publication peer review. For the current reviewing status please click here or scan the QR code on the right.

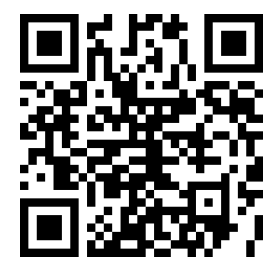

